\title{
Effects of melt pool variables and process parameters in laser direct metal deposition of aerospace alloys
}

Link to publication record in Manchester Research Explorer

\section{Citation for published version (APA):}

Salman, A., Pinkerton, A., Shah, K., \& Li, L. (2010). Effects of melt pool variables and process parameters in laser direct metal deposition of aerospace alloys. Materials and Manufacturing Processes, 25(12), 1372-1380.

\section{Published in:}

Materials and Manufacturing Processes

\section{Citing this paper}

Please note that where the full-text provided on Manchester Research Explorer is the Author Accepted Manuscript or Proof version this may differ from the final Published version. If citing, it is advised that you check and use the publisher's definitive version.

\section{General rights}

Copyright and moral rights for the publications made accessible in the Research Explorer are retained by the authors and/or other copyright owners and it is a condition of accessing publications that users recognise and abide by the legal requirements associated with these rights.

\section{Takedown policy}

If you believe that this document breaches copyright please refer to the University of Manchester's Takedown Procedures [http://man.ac.uk/04Y6Bo] or contact uml.scholarlycommunications@manchester.ac.uk providing relevant details, so we can investigate your claim.

\section{OPEN ACCESS}




\title{
Effects of Melt Pool Variables and Process Parameters in Laser Direct Metal Deposition of Aerospace Alloys
}

\author{
Kamran Shah ${ }^{1}$, Andrew J. Pinkerton ${ }^{1}$, Ahmad Salman $^{2}$, And Lin Li $^{1}$ \\ ${ }^{1}$ Laser Processing Research Centre, School of Mechanical, Aerospace and Civil Engineering, \\ University of Manchester, Manchester, United Kingdom \\ ${ }^{2}$ Machine Learning and Optimization Group, School of Computer Science, \\ University of Manchester, Manchester, United Kingdom
}

\begin{abstract}
Despite considerable advances in of laser direct metal deposition (LDMD) process optimization, there is rather limited work reported on the effects of melt pool variables on the final deposit characteristics. This article considers the effects of process parameters and melt pool characteristics on the deposition of Inconel 718 powder on a Ti-6Al-4V thin wall. A $1.5 \mathrm{~kW}$ diode laser and LDMD system is used to produce a series of deposits. Images of the process are captured using $\mathrm{Cu}$-vapor laser illumination and a high speed camera with long range microscopy optics, and quantitative results are extracted via image analysis. Process parameters such as carrier gas flow rate, powder mass flow rate and laser operating mode (CW and pulsed) and in process variables such as quantified melt pool disturbance, and final part characteristics are correlated and discussed. Scanning electron microscopy (SEM), electron backscatter diffraction (EBSD), and energy dispersive X-ray spectroscopy (EDS) are used to analyze deposited clads in terms of elemental composition and flow characteristics in the deposition melt pool. Melt pool disturbance is found to be a vital parameter in determining the surface roughness of the final part. An inverse relation between the mean surface disturbance of the melt pool and the surface roughness of the part is observed, and carrier gas flow rate and powder mass flow rate both affect the overall melt pool size. The work has implications for the selection of process parameters for commercial laser deposition processes-the speed with which powder is delivered to the melt pool as well as the mass flow rate may need to be taken into account when calculating build rate and for a good surface finish requiring minimum post process finishing a stable melt pool may actually be the worst situation.
\end{abstract}

Keywords Cladding; Deposition; Laser; Inconel; Ti-6Al-4V.

\section{INTRODUCTION}

Laser direct metal deposition (LDMD) is an additive technique based upon the mechanism of fusing metallic powders delivered by either a lateral or coaxial nozzle to a base metal or substrate to build three-dimensional objects directly from a computer aided design (CAD) model. The laser source can be either continuous wave or pulsed wave. The base metal or substrate is normally fixed to a Computer Numerical Controlled (CNC) table. A laser is fired onto the substrate, which creates a melt pool. Incoming powder from the nozzle is fused in the melt pool, which on solidification creates a layer. This process is repeated for a number of layers to create various geometries. With the use of LDMD, complex shapes with variable degrees of complexity can be easily realized $[1,2]$. Applications of the laser direct metal deposition process have been found in the aerospace and automotive industries for repair and tooling [3-6].

LDMD is a complex process involving a large number of parameters that can affect the final characteristics of a LDMD part. These final characteristics include deposition dimension, microstructure, mechanical properties, and the surface roughness. [6]. Control of these characteristics

Received February 10, 2010; Accepted March 8, 2010

Address correspondence to Mr. Kamran Shah, Laser Processing Centre (LPRC), Department of MACE, University of Manchester, Pariser Building, Manchester M60 1QD, UK; E-mail: kamranshah @ hotmail.co.uk requires a good understanding of the relationship between the independent process variables, such as laser power, beam parameters, transverse speed, powder feeding rate shielding gas speed, and the deposit properties such as track geometry, mechanical properties, surface roughness, and microstructure. Several authors have attempted to make the link via analytical [7], numerical or empirical means [8]. However, most of these studies considered the melt pool as quasi-stationary and thus do not consider factors that caused or resulted from pool instability. As examples, Resch et al. [9] investigated layer cross-section and surface roughness as a function of processing speed in blown powder process in continuous wave laser deposition, but did not consider the effects of the velocity of the blown powder on the final part or the comparison between continuous and pulsed wave deposition. Beuth and Klingbeil [10] experimentally measured melt pool length and produced process maps for thermal gradient and stresses. However, they did not consider the effect of incoming mass and gas flow rates and explained their results via Rosenthal's quasi-stationary solution. This article quantifies how closely the system actually resembles that "ideal" quasi-stationary state.

Reports have been published on the deposition processes with the laser operating in continuous wave $(\mathrm{CW})$ and pulsed wave modes [11-16], but there have been very few on comparison between the two. In two such works by Sun et al. [17, 18], the comparison between pulsed and continuous wave laser deposition mainly focused on fixed 
powder mass flow rates and average laser power. Pinkerton and $\operatorname{Li}[19,20]$ correlated the pulse width and frequency of the laser and the surface roughness of the samples. However, the work did not provide conclusive evidence of the effect of laser pulses on the surface roughness of the deposited part. There has been no comparative study of pulsed and CW laser deposition that also considers the effect of powder mass flow rate and powder carrying gas flow rates.

There has also been much emphasis on the control of power and traverse velocity of substrate/laser head in order to control the dimensional accuracy of the deposited tracks. Hua and Choi [21] employed closed real time optical height control system to effectively control the power of the laser beam to enhance surface roughness and dimensional accuracy. In their work, feedback control had a little effect on the surface roughness of the parts. Mazumder et al. [22] employed a three-sensor system to reduce the surface roughness of the fabricated parts, while Liu and Li [23] used an in-time motion strategy to improve the dimensional accuracy and surface finish in the laser cladding process. They did not consider the effect of laser pulsing or carrier gas flow rate in their work.

In this article, the effect of process variables including powder mass flow rate, conveyance gas flow rate, and beam mode on the melt pool are quantified using inprocess Charge-Coupled Device (CCD) imaging. The work examines the extent to which the pool deviates from its quasi-stationary state, with a transient, "unstable" component, and the consequences in terms of final part characteristics.

\section{EXPERIMENTAL PROCEDURE}

A series of experiments was performed, using various combinations of parameters to deposit Inconel 718 powder on a Ti-6Al-4V wall (Table 1). These alloys are both well known and widely used in the aerospace industry. Ti-6Al-4V (5.5-6.75\% Al, 3.5-4.5\% V, $0.4 \% \mathrm{Fe}, 0.2 \%$ $\mathrm{O}$, and balance $\mathrm{Ti}$ ) is a low-medium temperature alloy, commonly used in the front, low pressure stage of a turbine, while Nickel superalloys such as Inconel 718 $(50-55 \% \mathrm{Ni}, 17.2-21.0 \% \mathrm{Cr}, 18.5 \% \mathrm{Fe}, 3 \% \mathrm{Mo}, 5.1 \%$ $\mathrm{Nb}$, and $0.20-0.80 \% \mathrm{Al}$ ) have excellent high temperature properties and are more commonly seen in a turbine's combustion chamber region.

A $1.5 \mathrm{~kW}$ Laserline LDL 160-1500 diode laser, operated in both continuous and pulsed modes was used. In the pulsed mode the output was approximately a square wave defined by the period and pulse length (Table 1). The beam profile was measured using Prometec Laserscope UFF100 rotating hollow needle type diagnostic equipment. The beam intensity distribution in the focal plane was found to be top-hat in shape with a beam diameter of $1.59 \mathrm{~mm}$. The substrates were $50 \times 30 \times 10 \mathrm{~mm}^{3}$ blocks of Ti-6Al-4V, sandblasted in a Guyson sand blaster and then degreased using ethanol. The workpiece was tightly clamped and then mounted on a 3 axis CNC motion system.

The Ti-6Al-4V and Inconel 718 powders were both gas atomized, giving particles with approximately spherical morphology, and both had a powder size distribution of $53-150 \mu \mathrm{m}$. A FST PF-2/2 disk type powder feeder manufactured by Flame Spray Technologies Ltd. was used in experiments. An in-house build coaxial powder delivery nozzle fixed vertically above the motion system was used to deliver the powder. The deposition area was shrouded by an Argon gas flow from the nozzle. The gas pressure for all experiments was set to 5 bars with flow-rates

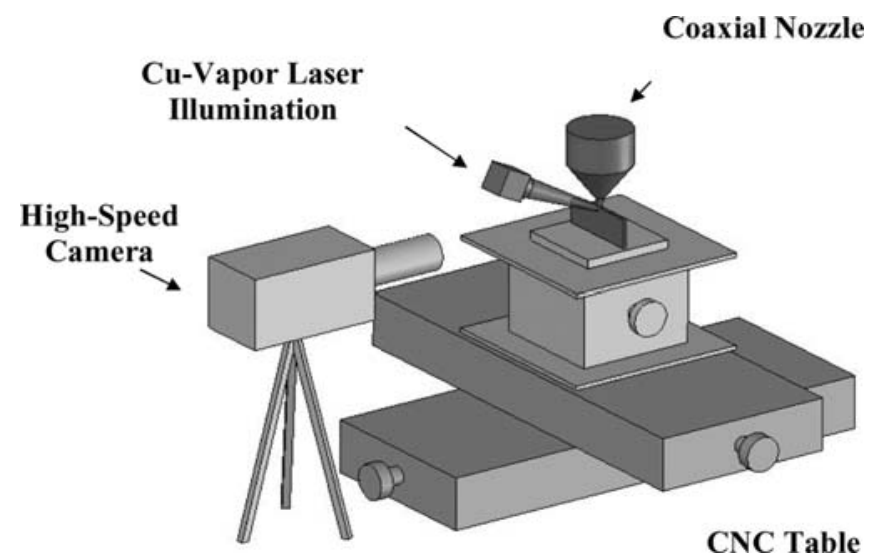

FIGURE 1.-Schematic of the experimental setup.

TABLE 1.-Experimental parameters used in the experiement.

\begin{tabular}{ccccccc}
\hline $\begin{array}{c}\text { Sample } \\
\text { no }\end{array}$ & $\begin{array}{c}\text { Peak power } \\
(\mathrm{W})^{A}\end{array}$ & $\begin{array}{c}\text { Pulse length } \\
(\mathrm{ms})\end{array}$ & $\begin{array}{c}\text { Period } \\
(\mathrm{ms})\end{array}$ & Duty cycle $^{B}$ & $\begin{array}{c}\text { Powder mass } \\
\text { flow rate }(\mathrm{g} / \mathrm{s})\end{array}$ & $\begin{array}{c}\text { Carrier gas } \\
\text { flow rate }(1 / \mathrm{s})\end{array}$ \\
\hline 1 & 600 & - & - & 1 & 0.179 & 0.067 \\
2 & 600 & - & - & 1 & 0.358 & 0.067 \\
3 & 600 & - & - & 1 & 0.537 & 0.067 \\
4 & 600 & - & - & 1 & 0.179 & 0.134 \\
5 & 600 & - & - & 1 & 0.358 & 0.134 \\
6 & 600 & - & - & 1 & 0.537 & 0.134 \\
7 & 1500 & 20 & 50 & 0.4 & 0.179 & 0.134 \\
8 & 1500 & 20 & 50 & 0.4 & 0.358 & 0.134 \\
9 & 1500 & 20 & 50 & 0.4 & 0.537 & 0.134 \\
10 & 1500 & 20 & 50 & 0.4 & 0.179 & 0.067 \\
11 & 1500 & 20 & 50 & 0.4 & 0.358 & 0.067 \\
12 & 1500 & 20 & 50 & 0.4 & 0.537 & 0.067 \\
\hline
\end{tabular}

Mean power $=600 \mathrm{~W}$ in all cases.

Duty cycle $=$ pulse length/period. 
between $0.067-0.1341 / \mathrm{m}$. The deposition scanning velocity of $5 \mathrm{~mm} / \mathrm{s}$ was maintained during the deposition of all the samples. Length of each deposited layers was kept at $40 \mathrm{~mm}$. Parameters used in the experiment are shown in Table 1.

Eight-millimeter high Ti-6Al-4V walls were initially built on Ti-6Al-4V substrate. On top of this wall, Inconel 718 layers were deposited. The whole process was captured at 10,000 frames per second (fps) as Audio Video Interleave (AVI) format data by a Photron Ultima APX high-speed camera. Illumination of the melt pool was provided by an Oxford Lasers copper vapor laser providing 511 and $578 \mathrm{~nm}$ wavelength light. A narrow pass filter in front of the camera was used to block all other wavelengths, and the camera and the copper vapor laser were synchronized for maximum illumination during the process. A schematic of the experimental setup is shown in Fig. 1. The recorded AVI files were analyzed, and a novel technique was developed using MATLAB to extract quantitative data on the surface disturbance of the melt pool.

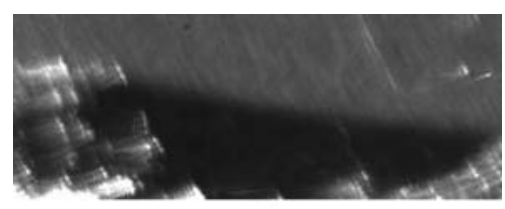

(a)

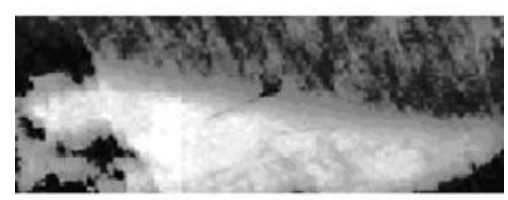

(b)

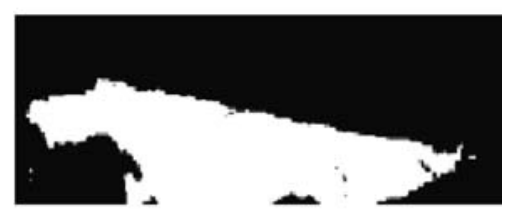

(c)

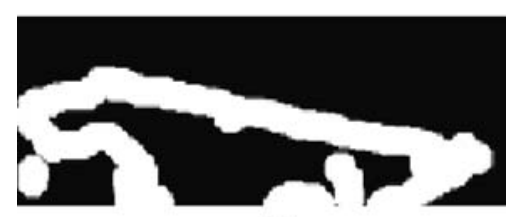

(d)

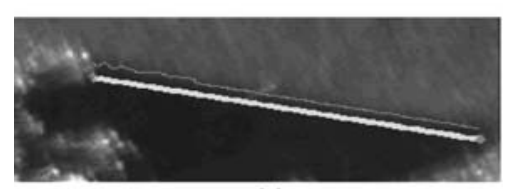

(e)

Figure 2.-(a)-(e) Flow chart of image analysis done on the melt pool. (a) Original image of the melt pool. (b) Grey scale image with increased contrast using histogram equalization. (c) Melt pool extraction using thresholding. (d) Edge detection. (e) Disturbance calculation (Redline) with reference to the pool surface along with longest line segment (green line).
One aim of the investigation was to measure the deviation/disturbance in the melt pool caused by the injected powder stream and other factors. Five frames at $0.1 \mathrm{~s}$ intervals were first extracted in bitmap format from each of the motion pictures taken by the high-speed camera. Each frame of the melt pool was closely cropped to select the area of interest and eliminate redundant noise in the image. These images were then converted to grayscale and underwent histogram equalization to increase the contrast. The aim was to allow the surface of the pool to be clearly discriminated from the rest of the image. The next step was edge detection of the melt pool. Edges were detected using the Canny method [24] which finds the edges in the image by looking for the local maxima of the image gradient. The gradient was calculated using the derivative of the Gaussian filter; this method uses thresholds to detect strong and weak edges. Weak edges are included only when they are connected to the strong edges. The advantage of using this technique is its robustness against noise [24]. After edge detection, the next step was to find the longest line segment, which corresponds to the surface of the metal pool in the images. To avoid discontinuities due to salt-n-pepper noise, it was necessary to dilate the image. The Standard Hough Transform [25] was then used to extract the line segments. A straight line was then fit to the longest line segment, starting and finishing at the limits of the pool (as if the surface had zero disturbances). Total melt pool disturbance was calculated by measuring the white pixels nearest to this line segment. All pixels related to the melt pool surface above or below the straight line were assumed to be the disturbance created by the injected powder. The system was initially calibrated to obtain the relation between dimensions within the image and number of pixels so the length of the pool and melt pool disturbance could be translated to SI units. A flow chart illustrating the above procedure is shown in Fig. 2. After the image analysis on each of the five frames, the average surface disturbance in the melt pool over time was calculated.

Surface roughness of the final samples was measured parallel to the deposition direction, on the top surface of the deposited wall. These were measured by an in-house laser-based scanning/profiling system with a resolution of $1 \mu \mathrm{m}$. Scanning electron microscopy (SEM) and electron backscatter diffraction (EBSD) were performed on the top surface of each sample.

Later, samples were cross-sectioned across the deposit, polished to $1 \mu \mathrm{m}$ finish, and separately etched using Kroll's reagent for Ti-6Al-4V and $10 \%$ oxalic acid solution for electrolytic etching using 6V DC for Inconel 718 part of the wall. Energy dispersive X-ray spectroscopy (EDS) analysis was performed for investigation of elemental distribution in the samples.

\section{RESUlts}

The mean melt pool surface disturbances with the laser in both continuous wave and pulsed wave mode are shown in the Fig. 3. This clearly shows a positive relationship between mass flow rate and mean surface disturbance. However, the magnitude of mean surface disturbance in the case of pulsed deposition is higher than continuous wave 


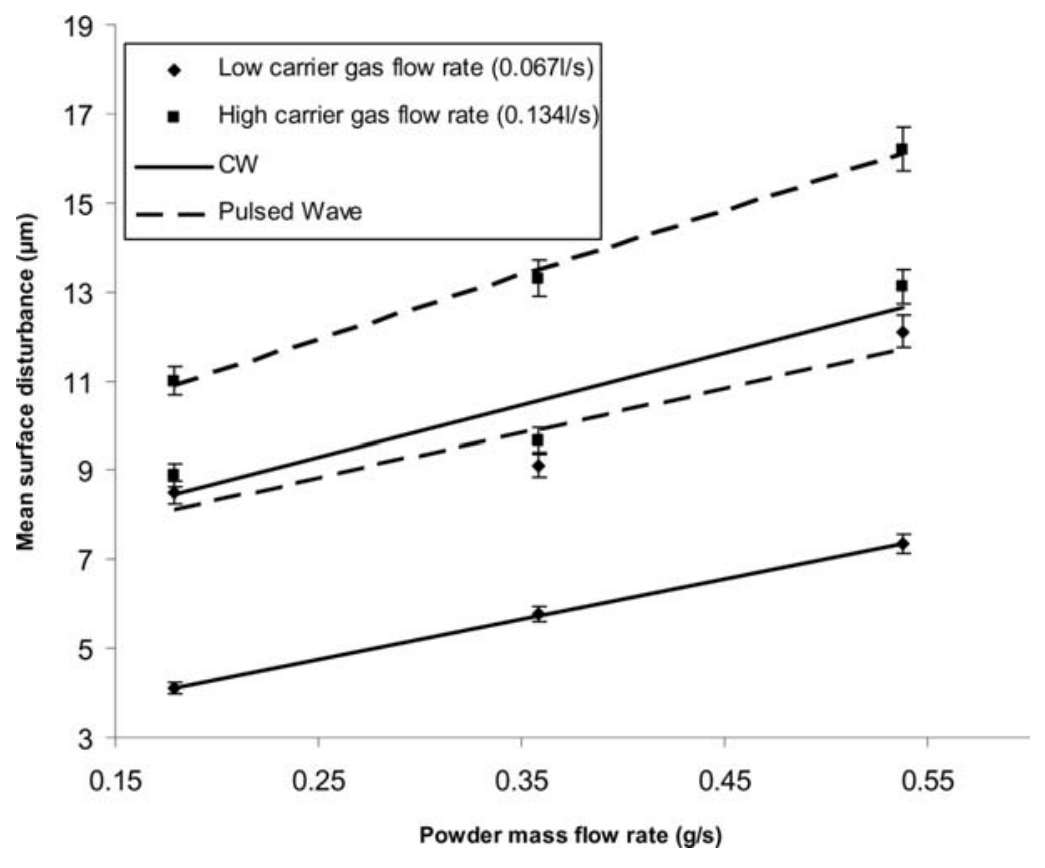

FIGURE 3.-Mass flow rate vs. mean surface disturbance.

deposition. Values of the mean surface disturbance in the case of high carrier gas flow rate are almost double the values obtained in the case of low carrier gas flow rate for both modes of laser operation.

The overall roughness of the top surface depends partly on the partially assimilated powder particles. These partially assimilated powder particles on the top surface of the wall are shown in Fig. 4.

Figure 5 shows the mean surface roughness of the samples produced by the continuous and pulsed wave deposition. This graph demonstrates that in both cases mean surface roughness decreases with an increase in powder flow rate for both continuous and pulsed wave deposition. The mean surface roughness is higher with a low velocity of carrier gas flow than with a high velocity of carrier gas flow. Overall, lower mean surface roughness is produced by pulsed wave mode deposition. The differences in surface roughness caused by carrier gas flow are smaller in pulsed wave deposition than continuous mode deposition.

Figure 6 depicts the effect of powder mass flow rate on the length of the melt pool in continuous and pulsed wave deposition. It is noted that length of the pool increases with powder mass flow rate during both pulsed and continuous wave deposition. The pool is longer with the low carrier gas flow rate than with the high carrier gas flow rate. This trend is observed during both continuous and pulsed wave deposition. At the same parameters, the mean pool length

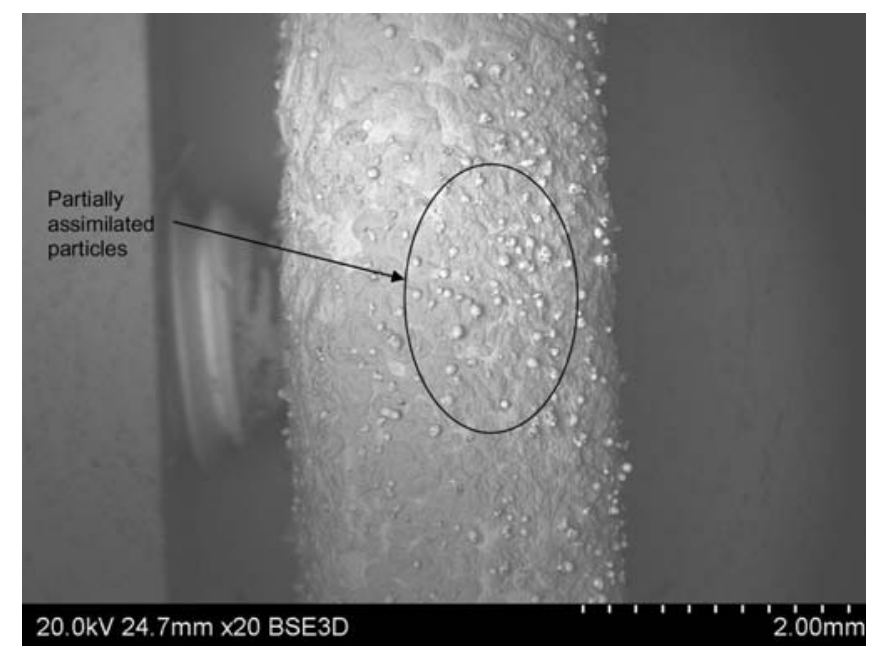

FIGURE 4.-Partially assimilated powder particles on top surface of the sample. 


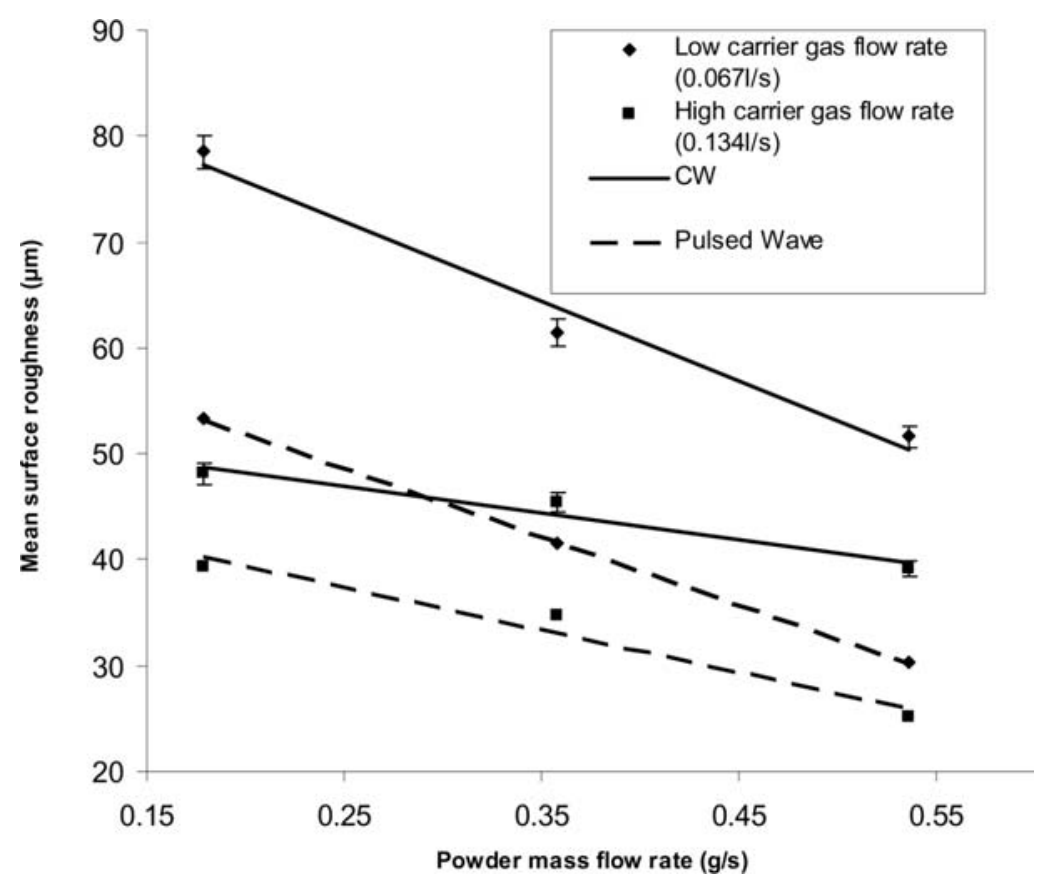

FiguRE 5.-Mass flow rate vs. mean surface roughness.

is longer during pulsed wave deposition than continuous wave deposition.

In Fig. 7, variation of the depth of the melt pool during pulsed and continuous wave deposition is shown. It is noted that the depth of the melt pool decreases with an increase of the powder mass flow rate. A high carrier gas flow rate has the effect of increasing the overall depth of the pool, compared to a low flow rate during both pulsed and continuous wave deposition.

Figure 8 shows the melt pool area variation during both continuous and pulsed wave deposition. It can be seen that in continuous wave deposition the area of the melt pool produced with a high carrier gas flow rate is larger than the area produced with a low gas flow rate. The area of the melt

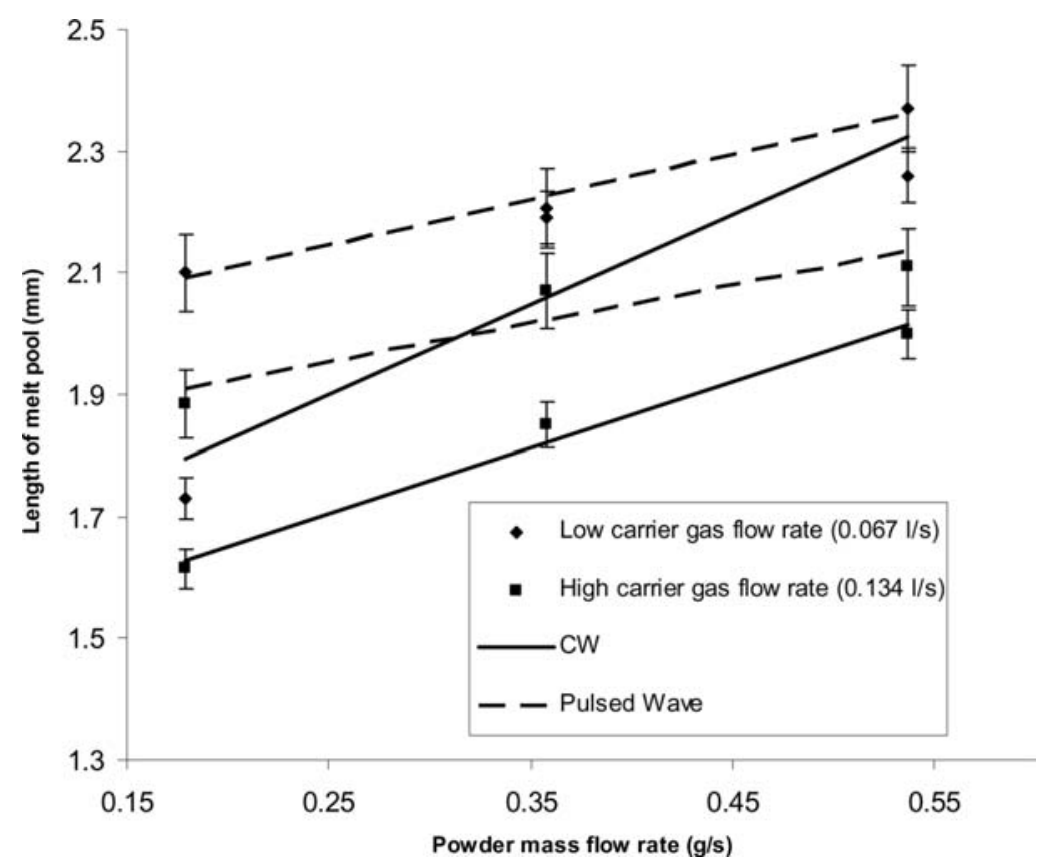

Figure 6.-Mass flow rate vs. length of the melt pool. 


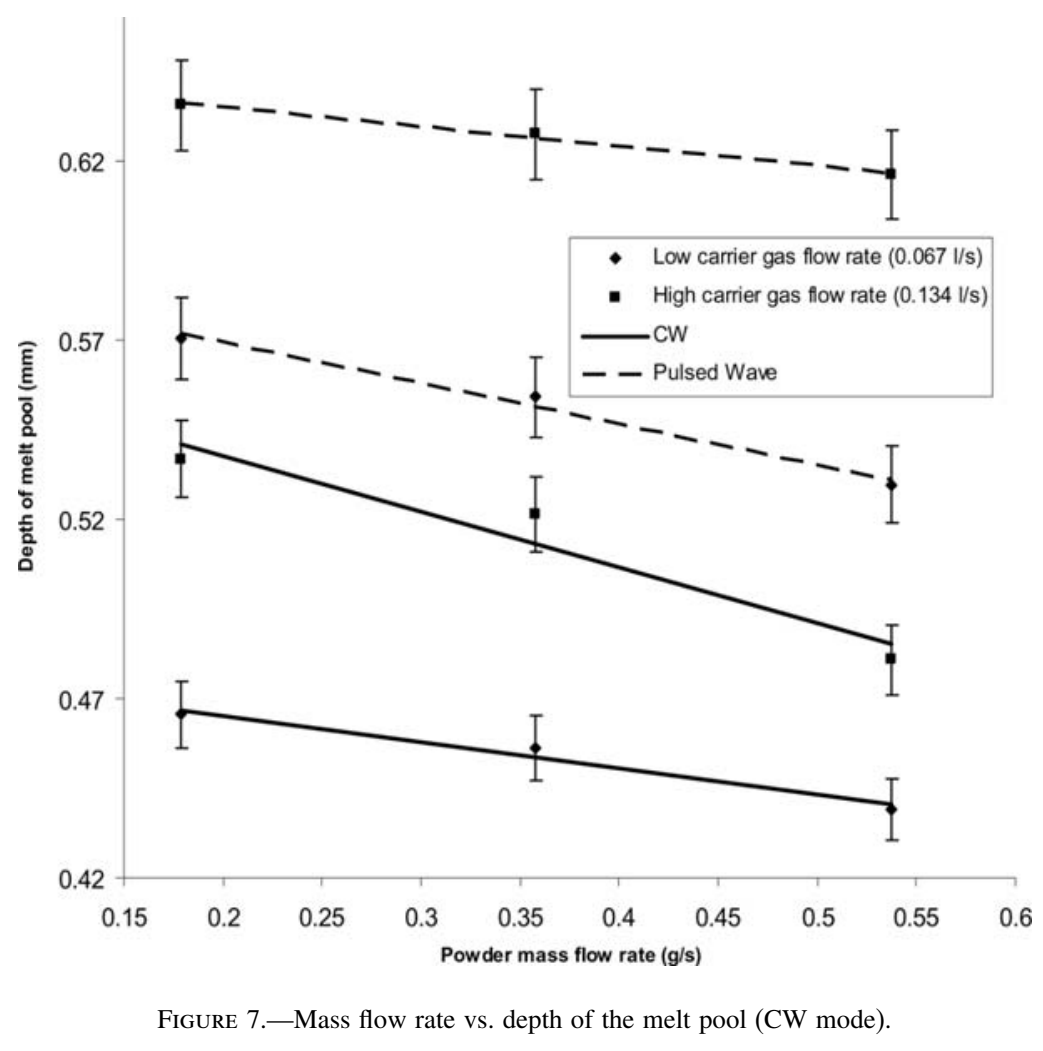

pool shows an increase with an increase in powder mass flow rate during the deposition process. The same is true of deposition in pulsed wave mode. Figure 8 illustrates melt pool area increases with increasing powder mass flow rate under conditions of high and low velocity of carrier gas. It is also noted that the melt pool area during pulsed wave deposition is higher than the melt area during the continuous wave deposition. This trend is observed under both low and high carrier flow rate conditions

Trends in EDX line scans suggest more mixing of $\mathrm{Ti}$ and $\mathrm{Ni}$ in case of pulsed deposition as compared to the continuous deposition. However, as shown in Figs. 9(a)

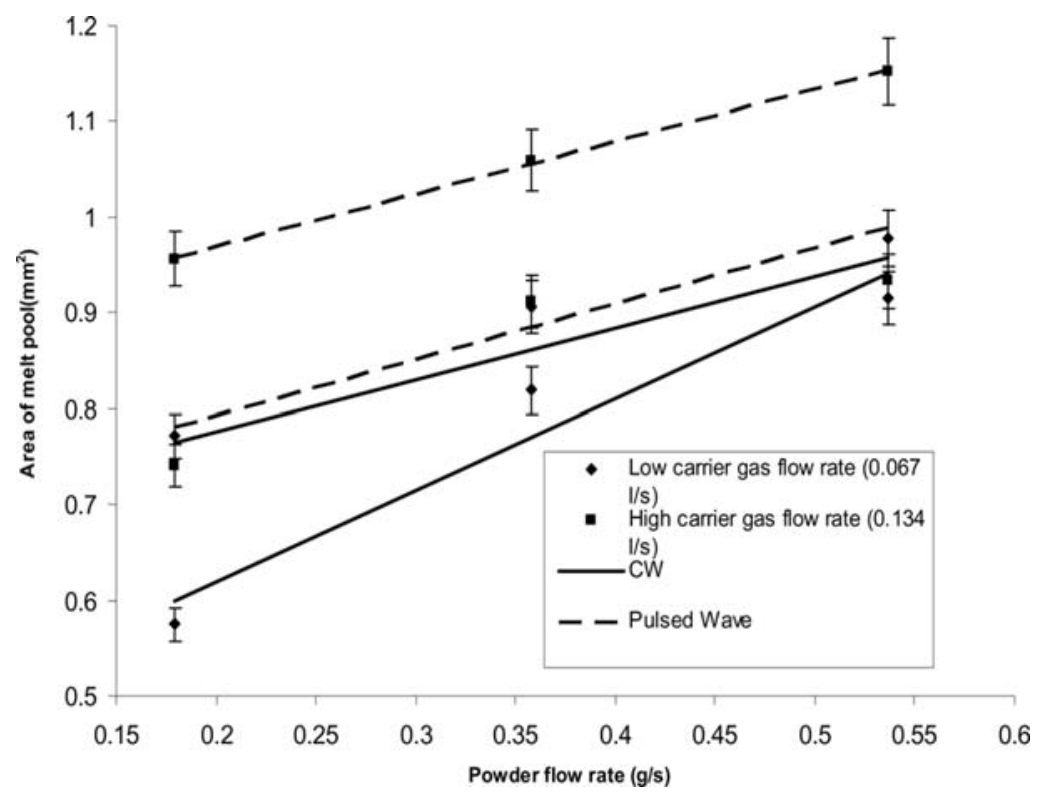

FIGURE 8.-Mass flow rate vs. area of the melt pool. 


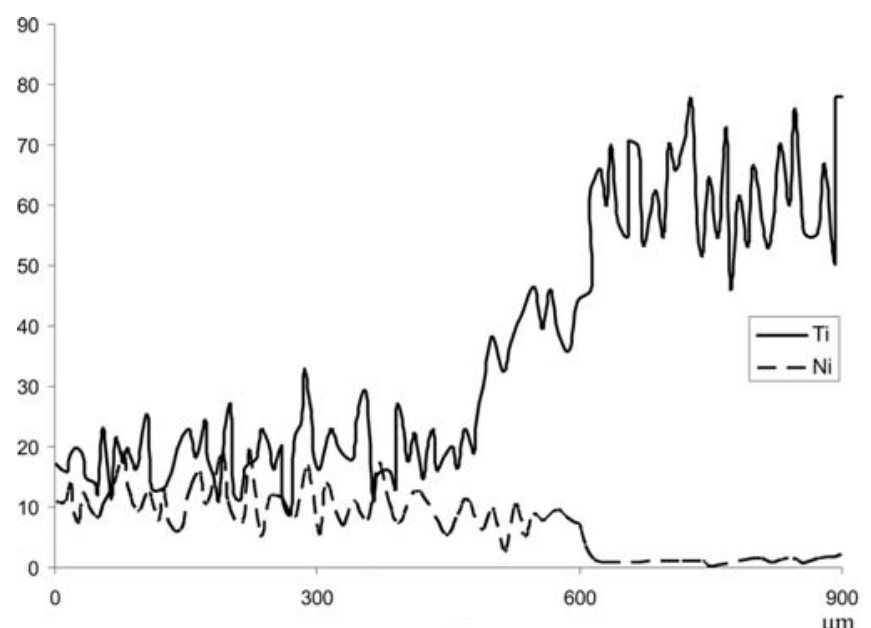

(a)

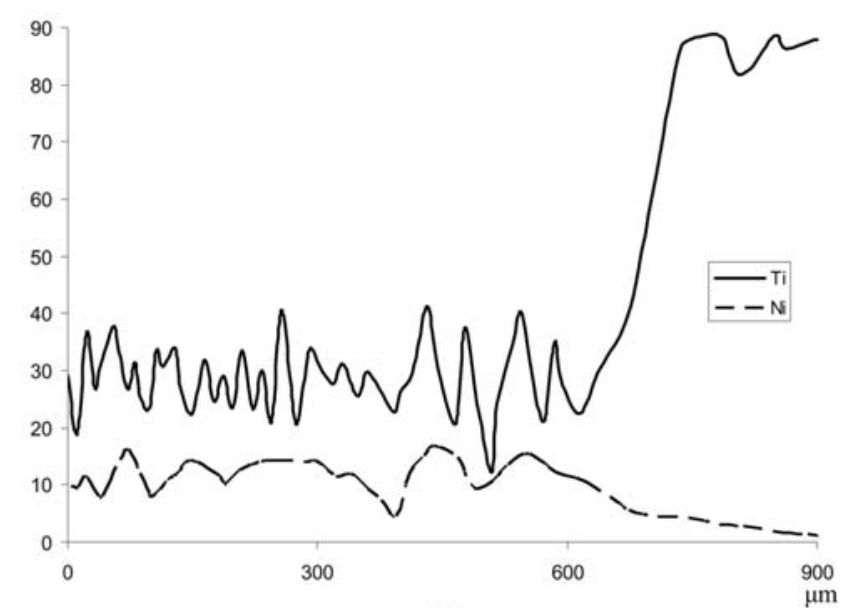

(b)

FIGURE 9.- (a) EDX line scan, change in gradient (CW deposition). (b) EDX line scan, change in gradient (pulsed wave deposition).

and (b), the gradient in elemental composition at the clad-substrate interface is not very different for the different laser modes.

\section{DiscUSSION}

\section{Melt Pool Surface Disturbance}

Surface disturbance in the melt pool and deviation from ideal quasi-stationary conditions can be caused by a variety of factors like Marangoni flow, powder flow impinging on the melt pool surface, turbulence in powder conveyance and shielding gases, and variable input power when the laser is in pulsed mode.

Experimental results suggest that the surface disturbance produced during the continuous and pulsed wave deposition plays an important role in determining the surface roughness of the final part. The mean surface disturbance obtained during pulsed deposition is high compared to that during continuous wave deposition, which effectively decreases the mean surface roughness of the final part. This is not the intuitive effect, but a higher surface disturbance of the melt pool may effectively enhance mixing and melting of the powder particles in the melt pool, preventing partially assimilated particles which are a common cause of increased roughness in LDMD. In addition, the melt pool during the pulsed deposition periodically experiences high temperature as compared to the continuous wave deposition [18], so it is possible that the surface is also partially remelted, removing powder particles that have stuck there.

Another important parameter that influences surface roughness of the parts is the carrier gas flow rate. It is noted that a high velocity of carrier gas flow causes increased surface agitation/disturbance at the melt pool surface and decreased surface roughness. Increased surface disturbance this time assisted by the speed of incoming particles at high flow rates may again increase assimilation reducing surface roughness by reduction of partially assimilated particles.

\section{Melt Pool Size}

Creation of the melt pool during the laser cladding is due to melting of the substrate and the powder impinging on and being assimilated into the melt pool. The negative correlation between powder mass flow and melt pool depth can be explained by the thermodynamics of the melt pool. With the increase in powder mass flow rate, the amount of heat absorbed by the substrate is decreased due to shadowing effect of the powder and the energy required to assimilate it to the melt pool. This causes the decrease in depth of the melt pool inside the substrate.

The increase in the length of the melt pool with powder mass flow rate can be attributed to the higher amount of melted powder. With the increase in powder mass flow, more powder is available to be melted, therefore increasing the length of the melt pool, provided that the process is in the mass limited parameter range [26] and laser power is sufficient to melt more powders [27].

The area of the melt pool is of course dependent on the combination of melt pool length and depth. The combined effect is for the melt pool area to increase with increasing powder flow rate, indicating that the increase in melt length is numerically more significant than the reduction in depth. This is not surprising: energy is used more efficiently melting powder than it is melting substrate, where conduction losses are significant. At higher powder mass flow, a greater proportion of energy reaching the substrate is conveyed as heated particles rather than the incident laser flux. This increase in the melt pool area is higher in magnitude in case of pulsed wave deposition as compared to the continuous wave deposition. This can be attributed to the above effect being very marked at the high peak power observed during the pulsed deposition process.

The effect of carrier gas flow rate on melt pool depth suggest that the increase in carrier gas flow rate increases the speed of powder hitting the melt pool that leads to deeper but shorter melt pool. But this increase in depth of the pool is numerically less significant than the reduction in length of the pool. This can be attributed to the change in powder flow characteristics and ricocheting powder.

The Marangoni flow in the pool is proportional to the square of the melt pool size and has significant implication for overall melt pool shape [28]. The increase in melt 
pool size in case of pulsed wave deposition suggests more vigorous Marangoni flow. This increase will not only ensure good mixing of elements within the melt pool but may also contribute to the increased agitation at the surface of the melt pool. EDX of the sample shows higher dilution and a greater proportion of Ti-6Al-4V elements in the melt pool in the case of pulsed deposition [Fig. 9(b)]. In both samples, there is an even distribution of Ti throughout the pool, suggesting vigorous Marangoni flow driven mixing.

\section{CONCLUSION}

High-speed imaging and image analysis of the melt pool during pulsed and continuous beam mode laser direct metal deposition of Inconel 718 on a Ti-6Al-4V thin wall allows the following conclusions to be drawn:

1. Increased powder flow rate, increased carrier gas flow rate, and using the laser in pulsed mode all increase the mean surface disturbance and affect the mean area of the melt pool by experiencing high peak power during pulsed deposition process.

2. There is an inverse relationship between the surface disturbance of the melt pool and the surface roughness of the part. It is suggested that increased melt pool disturbance can reduce the presence of partially assimilated surface particles and thus under the tested conditions had a beneficial effect for the process.

3. Under the tested conditions, which were identified as being in the mass-limited range of the process, the overall melt pool cross-sectional area increased with an increase in powder mass flow rate. The carrier gas flow rates also play a role in determining the melt pool size: an increase in gas flow rate leads to a melt pool that is shorter and has smaller cross-sectional area. This could be due to changes in powder stream characteristics causing less powder to impact on the melt pool or to or powder ricocheting from it.

\section{ACKNOWLEDGMENTS}

This work is towards the European Union FP6 project "FANTASIA" (agreement 030855) and FP7 IAPP project "INLADE" (agreement 230756). The authors would also like to acknowledge the assistance of the UK Engineering and Physical Sciences Research Council Loan Pool and Oxford Lasers for the high-speed imaging system that enabled the work. Kamran Shah is thankful for research funding by N-W.F.P University of Engineering \& Technology (Pakistan).

\section{REFERENCES}

1. Vilar, R. Laser alloying and laser cladding. Materials Science Forum 1999, 301, 229-252.

2. de Oliveira, U.; Ocelík, V.; De Hosson, J.T.M. Analysis of coaxial laser cladding processing conditions. Surface and Coatings Technology 2005, 197, 127-136.

3. Yamada, K.; Morisita, M.K.; Ikeda, T. Direct Diode Laser Cladding of Co Based Alloy to Dual Phase Stainless Steel for Repairing the Machinery Parts; 2003. USA: SPIE-Int. Soc. Opt. Eng.
4. Krantz, D.; Nasla, S.; Byrne, J.; Rosenberger, B. On-demand spares fabrication during space missions using laser direct metal deposition, 2001. USA: AIP.

5. Gao, S.Y.; Zhang, Y.Z.; Shi, L.K.; Du, B.L.; Xi, M.Z.; Ji, H.Z. Research on laser direct deposition process of Ti-6Al4V alloy. Acta Metallurgica Sinica (English Letters) 2007, 20, 171-180.

6. Hu, Y.; Chen, C.; Mukherjee, K. Innovative laser-aided manufacturing of patterned stamping and cutting dies: Processing parameters. Materials and Manufacturing Processes, 1998, 13 (3), 369-387.

7. Fathi, A.; Toyserkani, E.; Khajepour, A.; Durali, M. Prediction of melt pool depth and dilution in laser powder deposition. Journal of Physics D: Applied Physics 2006, 39 (12) 2613-2623.

8. Palumbo, G.; Pinto, S.; Tricarico, L. Numerical finite element investigation on laser cladding treatment of ring geometries. Journal of Materials Processing Technology 2004, 155-156 (1-3), 1443-1450.

9. Resch, M.; Kaplan, A.F.; Schuoecker, D. Laser-assisted Generating of Three-dimensional Parts by the Blown Powder Process; SPIE-Int. Soc. Opt. Eng.: USA, 2001.

10. Beuth, J.; Klingbeil, N. The role of process variables in laser-based direct metal solid freeform fabrication. JOM 2001, 53 (9), 36-39.

11. Hyoung-Keun, L. Effects of the cladding parameters on the deposition efficiency in pulsed Nd:YAG laser cladding. Journal of Materials Processing Technology 2008, 202 (1-3), 321-327.

12. Dinda, G.P.; Dasgupta, A.K.; Mazumder, J. Laser aided direct metal deposition of Inconel 625 superalloy: Microstructural evolution and thermal stability. Materials Science and Engineering: A 2009, 509 (1-2), 98-104.

13. Chang, S.S.; Wu, H.C.; Chen, C. Impact wear resistance of stellite 6 hardfaced valve seats with laser cladding. Materials and Manufacturing Processes 2008, 23 (7), 708-713.

14. Pinkerton, A.J.; Karadge, M.; Syed, W.U.H.; Lin, L. Thermal and microstructural aspects of the laser direct metal deposition of waspaloy. Journal of Laser Applications 2006, 18 (3), 216-26.

15. Paul, C.P.; Alemohammad, H.; Toyserkani, E.; Khajepour, A.; Corbin, S. Cladding of WC-12 Co on low carbon steel using a pulsed Nd:YAG laser. Materials Science and Engineering A (Structural Materials: Properties, Microstructure and Processing) 2007, 464 (1-2), 170-176.

16. Liu, Y.H.; Guo, Z.X.; Yang, Y.; Wang, H.Y.; Hu, J.D.; Li, Y.X.; Chumakov, A.N.; Bosak, N.A. Laser (a pulsed Nd:YAG) cladding of AZ91D magnesium alloy with $\mathrm{Al}$ and $\mathrm{Al} 2 \mathrm{O} 3$ powders. Applied Surface Science 2006, 253, (4) 1722-1728.

17. Sun, S.; Durandet, Y.; Brandt, M. Correlation between melt pool temperature and clad formation in pulsed and continuous wave Nd:Yag laser cladding of stellite 6. In PICALO 2004-1st Pacific International Conference on Applications of Laser and Optics. Laser Institute of America: Melbourne, VIC, Australia, 2004.

18. Sun, S.; Brandt. M. Comparison Between Continuous Wave and Pulsed Nd:YAG Laser Cladding of Stellite 6; Laser Institute of America: San Francisco, 2004.

19. Pinkerton, A.J.; Li, L. An investigation of the effect of pulse frequency in laser multiple-layer cladding of stainless steel. Applied Surface Science 2003, 208-209, 405-410. 
20. Pinkerton, A.J.; Li, L. The effect of laser pulse width on multiple-layer 316L steel clad microstructure and surface finish. Applied Surface Science 2003, 208-209 (SUPPL), 411.

21. Hua, Y.; Choi. J. Feedback Control Effects on Dimensions and Defects of H13 Tool Steel by DMD Process; Laser Institute of America: Jacksonville, FL, United states, 2003.

22. Mazumder, J.; Guo, Z.X.; Yang, Y.; Wang, H.Y.; Hu, J.D.; Li, Y.X.; Chumakov, A.N.; Bosak, N.A. Closed loop direct metal deposition: art to part. Optics and Lasers in Engineering 2000, 34 (4-6), 397.

23. Jichang, L.; Lijun, L. In-time motion adjustment in laser cladding manufacturing process for improving dimensional accuracy and surface finish of the formed part. Optics and Laser Technology 200436 (6), 477-83.
24. Canny, J. A computational approach to edge detection. IEEE Transactions on Pattern Analysis and Machine Intelligence 1986, PAMI-8 (6), 679-98.

25. Hough, P. Method and Means for Recognizing Complex Patterns; United States Patent Office, 1962.

26. Kaplan, A.F.H.; Weinberger, B.; Schuocker, D. Theoretical Analysis of Laser Cladding and Alloying; SPIE-Int. Soc. Opt. Eng.: USA, 1997.

27. DuPont, J.N.; Marder, A.R. Dilution in single pass arc welds. Metallurgical and Materials Transactions B: Process Metallurgy and Materials Processing Science 1996, 27 (3), 481-489.

28. Drezet, J.-M.; Pellerin, S.; Bezencon, C.; Mokadem, S. Modelling the Marangoni convection in laser heat treatment. Journal de physique. IV (Proceedings) 2004, 120, 299-306. 